\title{
Ethics
}

\section{An Ethical Analysis of Crisis in Chronic Pain Care: Facts, Issues and Problems in Pain Medicine; Part I}

James Giordano, PhD1, and Michael E. Schatman, PhD²

From: ${ }^{1}$ Georgetown University, Washington, DC, and ${ }^{2}$ College of Osteopathic Medicine, Yakima, WA.

Dr. Giordano is the SamueliRockefeller Professor, Departments of Medicine and Neurosciences, and Senior Scholar in Residence, Center for Bioethics,

Georgetown University Medical

Center, Washington, DC.

Dr. Schatman is Assistant

Professor, Department of Family

Medicine, Pacific Northwest

University of Health Sciences, College of Osteopathic Medicine, Yakima, WA.

Address correspondence:

Dr. James Giordano

Departments of Medicine and

Neurosciences

Georgetown University Medical

Center

4000 Reservoir Rd, Bldg D, Rm 238

Washington, DC 20057

E-mail: jg353@georgetown.edu

Disclaimer: This work was supported in part by a grant from the Laurance S. Rockefeller

Trust, an American Academy of

Pain Medicine-Pfizer National Visiting Professorship (Texas Tech University Health Sciences Center, Lubbock, TX), and funding from the Samueli Institute (1) Conflict of interest: None.

Manuscript received: 06/30/2008
We posit that in order to realistically, fully, and most positively affect the capability of implementing a more comprehensive paradigm of pain care it is necessary to: 1) recognize the complexity of chronic pain; 2) account for economic factors imposed upon the healthcare system, and 3) enable articulation of any paradigmatic revision within the contemporary medico-legal environment.

Three primary ethical problems arise from the interaction(s) of these contingencies namely 1) the under-treatment of pain, 2) the inappropriate over-utilization of pharmacologic agents and techniques, and 3) tensions and conflicts that develop within the relationships of pain medicine. All can lead to a failure of technically apt and ethically sound pain care.

This essay - the first in a 3-part series - employs the method of ethical analysis to approach the circumstances, issues, questions, and problems of contemporary practice of pain medicine, to allow insight(s) to the facts, define the agents involved, appreciate how problems are generated, and develop more thorough evaluation and articulation of potential resolutions. We contend that resolution of these problems must offer practical responses to the circumstances and issues. Such practicality entails affording "good" in ways that are grounded to the facts and realities of situations, and are not merely theoretical or conceptual.

Determining the "good" is the work of ethics - as systems and analyses of the moral decisional process. Ethics establishes norms and articulates their use in practice, and we opine that the distinction between the normative and applied is more of a continuum that is dependent upon case and circumstance(s). Given the variety of circumstances in the practice of pain medicine, no single ethical system would be totally adequate, and we believe a discursive approach to be most effective.

Subsequent papers in this series will describe the systems, structure, and function of a putative ethical infrastructure of pain medicine, and will attempt to illustrate how these could be articulated within an integrative paradigm of pain care.

Key words: Pain medicine, crisis, ethics, philosophy, sociology, humanities, chronic pain

Pain Physician 2008; 11:4:483-490 


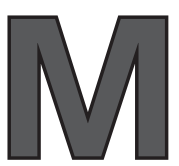

ayerfeld (1) has argued that there exists a general moral obligation to prevent or relieve human suffering. The original Code of Ethics published by the American Medical Association in 1847 states: "...from the age of Hippocrates to the present time, the annals of every civilized people contain abundant evidences of the devotedness of medical men to the relief of their fellow-creatures from pain and disease..." (2).

While some may question the universality of this obligation, few would argue the ethical responsibility of the pain physician to manage patients' pain and relieve suffering. Edwards (3) has suggested that, "...there is the duty to do all that can be done within the limits of current medical knowledge and available resources to relieve all the pain and suffering which can be alleviated" .

Yet, in this age of technophilic orientations to solving many if not all medical problems, an over-reliance on technology or purely objective assessment(s) can likely result in ineffective attempts to treat a patient's pain (4). In many ways, this reflects a dissonance, if not frank reluctance to confront the limitations and inadequacies borne of the technocentric, disease-based healthcare paradigm. Chronic pain frequently does not neatly "fit" into this model, but rather is more characteristic of phenomenal illness. As such, a more encompassing approach may be required that goes beyond simple focus upon the symptom or disease of pain, and entails evaluating and treating the person who suffers from pain.

We contend that in order to fully and most positively affect the capability (if not reality) of implementing a more comprehensive paradigm of pain care it is necessary to: 1) recognize the complexity of chronic pain, 2) account for economic factors imposed upon the healthcare system, and 3) enable articulation of any paradigmatic revision within the contemporary medico-legal environment.

\section{A Crisis in Pain Care: Time for Change}

Three primary ethical problems arise from the interaction(s) of these contingencies - namely 1) the under-treatment of pain (i.e., defensive practice), 2) the inappropriate over-utilization of various pharmacologic agents and techniques, and 3) the tensions and conflicts that develop within the proximate (i.e., patient and clinician) and second- and third-order relationships of pain medicine (i.e., between clinician, patient, and third party payer(s), attorneys, medical governing bodies, and state and federal agencies). All can lead to a failure of technically apt and ethically sound pain care. These problems are evidenced by a generalized lack of interest in chronic pain management among many physicians $(5,6)$, concerns regarding professional sanctions and legal action relating to the prescription of opioid analgesics (7-9), and a decrease in viable pain management programs due to the insurance industry's and hospital administrations' concerns with cost-containment and profitability when confronting long-term pain management $(10,11)$. As a result, pain care has become increasingly disjunct, broadly affecting pain medicine as a social good, with particular groups of patients - such as the poor $(12,13)$, certain racial and ethnic minorities (14-17), children (18-22), and older patients (23-26) - being at even greater risk for underservice and undertreatment.

Thus, while Congress has declared this to be the "Decade of Pain Control and Research" (H.R. 3244), and there has been increased interest in pain research, there is little compelling evidence to suggest that 1) federal funding priorities for basic and translational pain research have improved, 2) translational research applications are being articulated within an economically supportive healthcare system, 3) medico-legal guidelines and policies have been enacted to thoroughly address the issues and resolve the problems inherent to the practice of pain medicine, and 4) chronic pain is any less prevalent than 8 years ago $(27,28)$. In fact, some have suggested that the problem(s) of chronic pain are actually becoming worse (29). Given the capacity of technology to longitudinally manage chronic diseases, and the increased potential (if not likelihood) for patients who have these diseases to have an extended lifespan with durable chronic pain, medicine in general - and pain medicine more specifically - must ardently address the nature, multifold individual effects, and social, economic, and legal impact of intractable pain, and must confront the question of how to heal what cannot be cured. In this light, Ben Rich (30) has noted that "...the silence... of caregivers to adequately address pain in the clinical setting has been deafening." Taken together, these factors have led to what we consider to be a "crisis" - literally a "point at which change must come" — in chronic pain care in the United States.

If we are to develop a voice that calls for, and defines change in the practical and ethical conduct of pain medicine, then it becomes important to approach 
these problems with a sense of measure and purpose. In this essay, we employ the method of an ethical analysis to approach the circumstances, issues, questions, and problems that are drawn against the contemporary practice of pain medicine. This approach allows insight(s) to the facts that both underlie the circumstances and which help to define the agents involved, appreciation of how problems are generated at the intersection of agents in circumstance(s), and sustains a more thorough evaluation (and ultimate articulation) of potential resolution(s) of such problems.

\section{The Analysis}

\section{The "Facts" Pain as biological process}

Any analysis of an issue must begin with, and be built upon a recognition of facts (and perhaps a realization that such facts may be contingent and mutable) that are pertinent to the situation and relationships of involved agents. Thus, we posit that knowledge of pain - as symptom, disease, and/or illness - must be the basis for any and all constructs of pain medicine $(31,32)$. We have proposed that chronic pain may represent a spectrum disorder that entails co-morbid neuropsychological manifestations $(33,34)$. The expression of this pathologic spectrum is dependent upon genetic, environmental, and experiential interactions throughout the lifespan, and establishes individually unique patterns of physiological, cognitive, emotional, and behavioral responses to (pain as) disease and illness. Often, such co-morbidity presents as frank psychiatric disorder(s) (35), and we have posed that it is important to regard the underlying mechanisms of this spectrum disorder in order to appreciate the pre-disposition to, and co-presentation of, anxiety, mood, and substance abuse disorders in the chronic pain patient (36).

The pathologic process(es) of chronic pain may involve functional and structural activation and remodeling of neural networks involved in affect, cognition, and emotion. As well, changes in peripheral and central nociceptive and analgesic neuraxes can lead to changing thresholds and tolerance to pain. In this way, pathologic down-regulation of pain modulatory substrates would induce both altered patterns of pain and pain modulation (e.g., central sensitization, hyperpathia, allodynia, etc.), as well as diminished pharmacologic sensitivity to analgesic drugs, and could enhance the need for escalating doses of opioids and/or psychotropics. These mechanisms would elicit effects (e.g., rightward shifted opioid dose-response), and behaviors (e.g., apparent early-phase tolerance, rapid dose-escalation, drug seeking) that would appear to reflect non-responsiveness to treatment, non-compliance, and/or addiction (36-38).

\section{The "self" in pain}

This change in the neural basis of multiple domains of neural functions (e.g., sensation, perception, cognition, emotion, and perhaps more expansively, the basis of conscious processes that evoke the definable "self" ) contributes to the embodied person who is the patient in pain, defines the uniquity of their suffering, its impact and expression, and their needs $(39,40)$. As Nuala Kenny (41) notes "...suffering is an experience of persons...we must know persons...to come to some appreciation of their suffering. We cannot predict the source or severity of an individual's suffering from their diagnosis." In claiming that the responsibility of pain medicine as a practice is enacted within the relationship of circumstance(s), persons, actions and consequences, we have argued that the pain physician must not only understand pain, but must regard the effects that pain can incur on persons, and appreciate how pain manifests effects in a given patient (42). It is this contextualization that establishes the therapeutic and moral probity of the clinical encounter, and which provides the foundation for the trajectory of any and all care.

\section{Agents in Interaction \\ The pain patient}

Knowledge of the complexity of pain (as neural mechanism, symptom, disease, and illness) affords the clinician insight to how pain affects cognition, emotion, and behavior, and provides a "conceptual template" upon which specific patients' actual presentation of signs and symptoms can be based and evaluated. But ultimately, the reality of the clinical encounter must address the identity and agency of the person in pain. In other words we must ask: Who is this pain patient? How does pain affect this person, and how is it manifest and expressed?

Obviously, pain is defined by its noxiousness, and the adversity of hurting is the most fundamentally negative experience of pain. Yet, for many patients, an equally deleterious aspect of the chronic pain experience is the loss of function, which as Pullman (43) states "...can rob persons of ...capacity to pursue 
meaning-conferring endeavors" and purloin their capacity for activities, roles and relationships, independence, and for many, diminish the sense of personal agency and attributive dignity $(44,45)$. Undoubtedly, when an individual has historically been independent across multiple dimensions of functioning (including, but not limited to, activities of daily living, transportation, vocation, finances, etc.), the psychological and social consequences of such physical and economic dependence are likely to be profound. This change (or loss) of agency is compounded by the co-morbidities that frequently are expressed within the pain spectrum. Not only can psychological dysfunction (e.g., anxiety, depressive, and somatic characteristics and/ or frank disorders) and substance misuse/abuse elicit increasingly greater subjective "hurt" and suffering $(46,47)$, but these co-morbidities often incur negative stigmatization that may become implicitly (or explicitly) apparent even within the medical relationship.

\section{The pain clinician}

The pain clinician's claim to be a specialist invites the trust and reliance of the pain patient. In making this claim, the clinician not only declares a specific level of knowledge, and skill, but also affirms that this knowledge and capability will be used in ways that uphold the "good" of each and every (prospective) patient. We have opined that the pain clinician must utilize differing domains of knowledge in distinct ways and with appropriate balance to comprehend pain and discern its effects and expressions in the patient (48). While a mechanistic knowledge of pain can be objectively acquired, the effects of pain on the life world of a given patient require subjective insight. It is the combination of objective and subjective information that allow the clinician to 1) determine "the good" relative and relevant to a particular patient's (biomedical, psychological, and social) needs, values, and goals, and 2) direct the best (i.e., most technically right, and morally sound) course of care.

But the pain clinician is a person in her own right, with values, and dispositions that dictate her moral compass. How will she use her specialized knowledge? How will she enact the promise of profession in practice? In many ways, this speaks to what it means to "be" a pain physician. At the fore is a responsibility to both acknowledge the enigmatic nature of pain and its effects, and realize that the pain patient often co-presents with psychological and/or substance use issues that can complicate diagnosis and treatment. These complications heighten the vulnerability of the pain patient, and deepen the therapeutic and moral obligations of the clinician.

Clearly, unconditional positive regard is essential to any clinical practice (49), but even so, it is important to acknowledge that socio-cultural experiences can, and frequently do, shape the values and expectations of clinicians (50). We have stated previously, and reiterate here that "...the physician who enters the field of pain medicine does so by choice" (51). Thus, on an elementary level, we contend that the values of the pain clinician must be consistent with attending to the exigencies of the pain patient (e.g., psychological comorbidity, potential for substance misuse/abuse).

\section{The community of patient and clinician}

That needn't mean that the values of clinician and patient must concur, but rather that clinician and patient should develop and work toward realistic goals that the patient has identified, and which are based upon the premise of shared intentionality of pain relief and/or effective management and healing (52-54). Nor does this create any undue assumptions about what is required of the pain patient, who, in his/her state of vulnerability, might not be expected to be responsible for anything more than respect, and a commitment to the construct, goals, and ends of the medical relationship $(54,55)$.

The patient is driven to the clinician out of need, while the clinician freely enters the practice of pain care because of an intellectual and emotional identification with, and dedication to, helping and healing persons in pain. This fiduciary establishes the patient and clinician de communitas - "in community" (56, 57). Such sense of community is based upon the shared identification of "good" that is achievable within the relationship, and in this way the relationship is both therapeutic and moral - the clinician must seek to provide biomedical good in ways that allow equal appreciation for patients' values, goals, and choices, and which convey respect for the patient as a person (57). In the ideal, the "healing agency" of the clinician engenders the restored personal agency of the patient.

But the medical relationship is not enacted in a vacuum, and so even the most aligned values and interactive agency of patient and clinician are subject to the intentions and acts of agents and forces external to the clinical encounter. To be sure, the values and 
relative power of patient and clinician are asymmetrical to begin with, and given that pain medicine exists within a social environment, socio-economic and sociolegal factors frequently become the source and/or instigation of ethical issues and problems within clinical practice. Thus, if we are to catalyze change, we must look to the practice of pain medicine - writ large as a social good, and small as the individual good(s) rendered within the clinical encounter - to identify the issues and problems that impede progress, elucidate the causes and consequences of these issues and problems, and develop resolutions that are most well-informed, practical, and morally sound.

\section{The Nature of the Issues and Problems}

The ethical, economic, and legal boundaries of these issues and problems are not clearly demarcated. Instead, these domains tend to be reciprocally influential. A number of convergent forces have created the social environment, and set the stage for the ethical problems of contemporary medical practice, including 1) the progressive rise in market values and the business ethic as a consequence of the second industrial revolution; 2) fortification of market incentives of time-restriction and cost-efficiency fostered by an increasing reliance upon technology and technocentric mindset; 3) a renewed interest in patient autonomy that has been spawned, at least partly, by legal response to socio-medical misconduct in the twentieth century (e.g., medical crimes against humanity, resulting in the Nuremburg Code, Belmont Report, etc.), and a strongly libertarian anti-paternalistic sentiment, and 4) an increasingly litigious social climate, that ultimately relegates medicine to business conduct, and imposes contractual regulations upon medical practice(s) (58).

That economic influences have significantly affected the subsidy, and conduct of pain medicine (i.e., both research and practice) is undeniable, and despite the congressional incentive for "Pain Control and Research," the diversity (and perhaps appropriateness) of pain care has not been meaningfully enhanced. In many ways, this is a reflection of how market effects (e.g., short-term vs long-term cost and benefit analyses, prohibitive third-party payer regulations, etc.) that have negatively impacted the provision and availability of viable resources for treating and managing chronic pain. Diminishing resources coupled to an increasing need and demand for pain-related services have commodified the practice of pain medicine (a trend also seen in medical practice, at large) and have established the clinician as "provider" and patient as "client" (59).

This has hobbled professional responsibility and capacity in 3 ways: First, it has led to a somewhat bastardized conceptualization of patient autonomy to be construed as "the right of unrestricted free choice," rather than the dignity of independent action and agency and/or (albeit somewhat more narrowly defined) the negative right to refuse care that is offered. Second, the primacy of the patients' best interests is often subordinated to an economically-driven decisional process that has created supply-demand discrepancies; and third, these factors have prompted increasingly contractual, if not litigious, undertones that have progressively affected the scope, type, and nature of pain care.

In the main, this has led to the notion of "patient as consumer," that has created a direct tension between the expert knowledge and actions of the clinician, and the choices and behaviors of the patient. The medical relationship is based upon the definable medical needs of the patient, and the clinician's abilities to assess these needs and provide proper, safe, and sound treatment(s). Consumerism has resulted in an escalating pressure to provide treatments that patients view as being of "greatest value" (viz., facilitating the greatest "return" - i.e., perceived subjective effect - in light of investment of time and cost incurred by delays in receiving care, non-appropriation of benefits, etc.). Often the "high value" treatments requested/demanded are opioids and/or excessive interventional techniques (including surgery). This can lead to an overutilization of agents and procedures in an attempt to accommodate patient demands (i.e., acquiescent care, in which patient "autonomy" trumps that of the clinician to exercise prudent expert use of knowledge and skill). Characteristically this is prompted by patients' fears of escalating pain, diminishing resources, and availability of care, and by clinician's fears of legal retribution by "unsatisfied" patients $(58,59)$.

As well, underutilization/provision of agents and procedures is equally prevalent and none the less problematic. In this case, restricted treatment can result from 1) diminishing or non-available (fiscal and/or clinical) resources; 2) inadequate third-party coverage schemes; 3) clinicians' fears of medico-legal sanction 
and prosecution, 4) clinicians' mistrust of patients' capacities to abuse "autonomy," and/or 5) clinicians" discomfort of losing control of the medical situation (60-62).

\section{Toward Resolution: The Need for Practical Ethics}

At least part of the problem stems from a lack of cohesion in pain medicine, ranging from practice models and settings to inadequate policy and economic support for research and clinical care. Resolution of these problems must offer practical responses to the circumstances and issues. By definition, such practicality entails affording "good" in ways that are grounded to the facts and realities of situations and that are not merely theoretical, conceptual, or implausible. In this way, any attempt at resolving these problems must acknowledge technological advances, their applications, limitations, and effects, and must equally exhibit sensitivity to the social and personal factors that characterize pain medicine $(60,62)$. Determining what is "good" is the work of ethics - as systems and analyses of the moral decisional process. Ethics both establishes norms and articulates their use in practice, and thus the distinction between the normative and applied is nominal at best (63), and as matter of fact is more of a continuum of expression that is dependent upon case and circumstance(s). Given the variety of circumstances in the clinical practice of pain medicine, no single ethical system would be totally adequate, and a discursive approach is likely to be most useful and effective. It may be that what is actually needed is a meta-ethics of pain medicine, despite the onerous nature of such an undertaking. But for a meta-ethics to have any applied value and validity, it must be equally committed to the facts, realities, and contingencies of pain medicine as profession and practice, and therefore must incorporate an ethical "infrastructure and function" that engages ethical systems and approaches in ways that support and sustain the good to be provided on individual and public levels $(64,65)$. Subsequent papers in this series will describe the systems, structure, and function of this ethical infrastructure of pain medicine, and will attempt to illustrate how these approaches could be articulated within an integrative paradigm of pain care.

\section{Acknowledgments}

This work was supported in part by a grant from the Laurance S. Rockefeller Trust, an American Academy of Pain Medicine-Pfizer National Visiting Professorship (Texas Tech University Health Sciences Center, Lubbock, TX), and funding from the Samueli Institute (JG). The authors thank Sherry Loveless for her administrative and editorial assistance in the preparation of this manuscript. 


\section{References}

1. Mayerfeld J. The incrementalist argument for a strong duty to prevent suffering. J Soc Philos 1997; 28:5-21.

2. American Medical Association. Code of Medical Ethics of the American Medical Association. American Medical Association Press, Chicago; 1847.

3. Edwards RB. Pain and the ethics of pain management. Soc Sci Med. 1984; 18:515-523.

4. Giordano J. Technology in pain medicine: Research, practice, and the influence of the market. Prac Pain Management 2008; 8;56-59.

5. Potter M, Schafer S, Gonzalez-Mendez E, Gjeltema K, Lopez A, Wu J, Pedrin R, Cozen M, Wilson R, Thom D, CroughanMinihane M. Opioids for chronic nonmalignant pain. Attitudes and practices of primary care physicians in the UCSF/ Stanford Collaborative Research Network. University of California, San Francisco. J Fam Pract 2001; 50: 145-151.

6. Upshur CC, Luckmann RS, Savageau JA. Primary care provider concerns about management of chronic pain in community clinic populations. J Gen Intern Med 2006; 21:652-655.

7. Skelly FJ. Fear of sanctions limits prescribing of pain drugs. American Medical News 1994; 15:19.

8. Joranson DE, Carrow GM, Ryan KM, Schaefer L, Gilson AM, Good P, Eadie J, Peine S, Dahl JL. Pain management and prescription monitoring. J Pain Symptom Manage 2002; 23:231-238.

9. Fishman SM. Risk of the view through the keyhole: There is much more to physician reactions to the DEA than the number of formal actions. Pain Med 2006; 7:360-362.

10. Schatman ME. The demise of multidisciplinary pain management clinics? Prac Pain Management 2006; 6:30-41.

11. Schatman ME. The demise of the multidisciplinary chronic pain management clinic: Bioethical perspectives on providing optimal treatment when ethical principles collide. In: Schatman ME, (ed.) Ethical Issues in Chronic Pain Managemen Informa, New York, 2006, p.43-62.

12. Jost TS. Public financing of pain management: Leaky umbrellas and ragged safety nets. I Law Med Ethics 1998; 26:290-307.

13. Zerzan J, Stearns S, Hanson L. Access to palliative care and hospice in nursing homes. JAMA. 2000; 284:2489-2494.

14. Tait RC, Chibnall JT, Andresen EM, Hadler NM. Management of occupational back injuries: Differences among African Americans and Caucasians. Pain 2004; 112:389-396.

15. Chibnall JT, Tait RC, Andresen EM, Hadler NM. Race and socioeconomic differences in post-settlement outcomes for African American and Caucasian Workers' Compensation claimants with low back injuries. Pain 2005; 114:462-472.

16. Taylor BA, Casas-Ganem J, Vaccaro AR, Hilibrand AS. Hanscom BS, Albert TJ. Differences in the work-up and treatment of conditions associated with low back pain by patient gender and ethnic background. Spine 2005; 30:359-364.

17. Chibnall JT, Tait RC, Andresen EM, Hadler NM. Race differences in diagnosis and surgery for occupational low back injuries. Spine 2006; 31:1272-1275.

18. Hilgard JR, LeBaron S. Relief of anxiety and pain in children and adolescents with cancer: Quantitative measures and clinical observations. Int J Clin Exp Hypn 1982; 30: 417-442.

19. McGrath PA, Hillier LM. The enigma of pain in children: An overview. Pediatrician 1989; 16:6-15.

20. Schecter NL. The undertreatment of pain in children: An overview. Pediatr Clin North Am 1989; 36:781-794.

21. Howard RF. Current status of pain man agement in children. JAMA. 2003; 290: 2464-2469.

22. Schechter N. Untreated pain in children. In: Schmidt RF, Willis WD, (eds.) Encyclopedic Reference of Pain, SpringerVerlag, New York, 2006.

23. Bernabei R, Gambassi G, Lapane K, Landi F, Gatsonis C, Dunlop R, Lipsitz L, Steel K, Mor V. Management of pain in elderly patients with cancer. SAGE Study Group. JAMA 1998; 279:18771882.

24. Desbiens NA, Wu AW, Broste SK, Wenge NS, Connors AF Jr, Lynn J, Yasui Y, Phillips RS, Fulkerson W. Pain and satisfaction with pain control in seriously ill hospitalized adults: Findings from the SUPPORT research investigations. Crit Care Med 1996; 24:1953-1961.

25. Feldt KS, Ryden MB, Iles S. Treatment of pain in cognitively impaired compared with cognitively intact older patients with hip fracture. J Am Geriatr Soc 1998; 46:1079-1085.
26. McCaffery M, Ferrell BR. Patient age: Does it affect your pain-control decisions? Nursing 1991; 21:44-48.

27. Mularski RA, White-Chu F, Overbay D, Miller L, Asch SM, Ganzini L. Measuring pain as the 5 th vital sign does not improve quality of pain management. J Gen Intern Med 2006; 21:607-612.

28. Green CR, Wheeler JR, LaPorte F, Marchant $\mathrm{B}$, Guerrero E. How well is chronic pain managed? Who does it well? Pain Med 2002; 3:56-65.

29. Hurwitz W.E. Pain control in the police state of medicine (Part II). J Am Phys Surg 2003; 8:13-15.

30. Rich BA. A legacy of silence: Bioethics and the culture of pain. J Med Humanit 1997; 18:233-259.

31. Giordano J. Understanding pain as disease and illness; Part 1 Prac Pain Management 2006; 6:70-73.

32. Giordano J. Pain, the patient and the practice of pain medicine: The importance of a core philosophy and virtuebased ethics. In: Schatman M. (ed.) Ethical issues in Chronic Pain Management. Informa, NY, 2006 p. 1-18.

33. Giordano J. A big picture: Neurogenesis, pain and the reality and ethics of pain medicine. Prac. Pain Management 2007; 7:37-52.

34. Wurzman R, Jonas WB, Giordano Chronic pain as spectrum disorder. Pain Practitioner 2008, in press.

35. Giordano J, Wurzman R. Neurological disease and depression: The possibility and plausibility of putative neuropsychiatric spectrum disorders. Depression: Mind and Body 2008; 4:2-5.

36. Manchikanti L, Giordano J, Fellows B, Manchukonda R, Pampati V. Role of psychological factors as predictors of opioid abuse and illicit drug use in chronic pain patients. J Opioid Management 2007; 3:89-101.

37. Giordano J. Wurzman R. Chronic pain and substance abuse: Spectrum dis order and implications for ethical care. Prac Pain Management 2008; 8:53-58.

38. Manchikanti L, Atluri S, Trescot A, Giordano J. Monitoring opioid adherence in chronic pain patients: Tools, techniques and utility. Pain Physician 2008; 11:1-26.

39. Giordano J. Complementarity, brainmind, and pain. Forsch Komplmentmed 2008; $15: 2-6$.

40. Chapman CR. Psychological aspects 
of pain: A consciousness studies perspective. In: Pappagallo M. (ed.) The Neurological Basis of Pain, McGrawHill, 2005, NY, p. 157-170.

41. Kenny NP. Ethical implications of human suffering. Hum Health Care Int. 1997; 13:27-30.

42. Giordano J. On knowing: Domains of knowledge and intellectual virtue in practical pain management. Prac Pain Management 2006; 6:65-67.

43. Pullman D. Human dignity and the ethics and aesthetics of pain and suffering. Theoret Med 2002; 23:75-94.

44. Harris S, Morley S, Barton SB. Role loss and emotional adjustment in chronic pain. Pain 2003; 105:363-370.

45. Giordano J. Dignity, and pain medicine at the end of life. Prac Pain Management 2006; 6:68-70.

46. Katz PP, Yelin EH. Activity loss and the onset of depressive symptoms: Do some activities matter more than others? Arthritis Rheum 2001; 44:11941202.

47. Koob GF, Le Moal M. Drug addiction, disregulation of reward, and allostasis. Neuropsychopharmacol 2001; 24:97129.

48. Arnaert A, Ciccotosto G. Response phases in methadone treatment for chronic nonmalignant pain. Pain Manag Nurs 2006; 7:23-30.

49. Corey G, Corey MS, Callanan P. Issues and Ethics in the Helping Professions, 6th ed. Brooks/Cole, Pacific Grove CA,
2003.

50. Engebretson J, Monsivais D, Mahoney JS. The meaning behind the words: Ethical considerations in pain management. Am J Pain Manage 2006; 16:21 28.

51. Giordano J. Moral agency in pain medicine: Philosophy, practice and virtue. Pain Physician 2006; 9:41-46.

52. Waters D, Sierpina VS. Goal-directed health care and the chronic pain patient: A new vision of the healing encounter. Pain Physician 2006; 9:353360.

53. Fulford W. Ten principles of value based medicine. In: Radden J (ed.) Philosophy of Psychiatry: A Companion. Oxford, NY, 2004; p. 205-234.

54. Giordano J. Changing the practice of pain medicine writ large and small through identifying problems and establishing goals. Pain Physician 2006; 9:283-285.

55. Giordano J. The good patient: Responsibilities and obligations of the patientphysician relationship. Prac Pain Management 2007; 7:58-65

56. Giordano J. The moral community of the clinical pain medicine encounter. Prac.Pain Management 2006; 6:60-63.

57. Pellegrino ED. The healing relationship: The architectonics of clinical medicine. In: Shelp E (ed.) The Clinical Encounter: The Moral Fabric of the Patient-Physician Relationship. D. Reidel, Dordrecht, Netherlands, 1983; p. 153-172.
58. Beauchamp TL. The origins, goals, and core commitments of The Belmont Report and Principles of Biomedical Ethics. In: Walter JK, Klein EP. (eds.) The Story of Bioethics: From Seminal Works to Contemporary Explorations. Georgetown University Press, Washington, DC, 2003; p.17-46.

59. Pellegrino ED. The commodification of medical and health care: The moral consequences of a paradigm shift from a professional to a market ethic. J Med Phil 1999; 24: 243-266.

6o. Giordano J. Grappling with the ethics of practical pain management. Prac Pain Management 2008; 8:72-75

61. May T. Autonomy, Authority and Moral Responsibility. Kluwer, Dordrecht, The Netherlands, 1998.

62. Giordano J, LeRoy P, Uthaman U. On the role of primary care within a system of integrative multi-disciplinary pain management. Prac Pain Management 2006; 6:66-69.

63. Kagan S. Normative Ethics. Boulder, CO, Westview Press, 1998.

64. Maricich Y, Giordano J. Pain, suffering and the ethics of pain medicine: Is a deontic foundation sufficient? Am J Pain Managemen, 2007; 17:130-138.

65. Giordano J. A meta-ethics of pain medicine: Structure of the profession, function of the practice. In: Giordano J. (ed). Maldynia: Multi-Disciplinary Perspectives on the Illness of Chronic Pain. Informa, NY, in press. 